\title{
Assessment of Medical Screening and Clinical Reasoning Skills by Physical Therapy Students in a Simulated Patient Encounter
}

Therese E. Johnston

Thomas Jefferson University, therese.johnston@jefferson.edu

Follow this and additional works at: https://nsuworks.nova.edu/ijahsp

Part of the Medical Education Commons, and the Physical Therapy Commons

\section{Recommended Citation}

Johnston TE. Assessment of Medical Screening and Clinical Reasoning Skills by Physical Therapy Students in a Simulated Patient Encounter. The Internet Journal of Allied Health Sciences and Practice. 2018 Jan 01;16(2), Article 10.

This Manuscript is brought to you for free and open access by the College of Health Care Sciences at NSUWorks. It has been accepted for inclusion in Internet Journal of Allied Health Sciences and Practice by an authorized editor of NSUWorks. For more information, please contact nsuworks@nova.edu. 


\title{
Assessment of Medical Screening and Clinical Reasoning Skills by Physical Therapy Students in a Simulated Patient Encounter
}

\begin{abstract}
Purpose: Physical therapists (PTs) screen their patients for medical issues that may present as musculoskeletal conditions. In physical therapy education, learning activities followed by assessment of skills and clinical reasoning is important. The purposes of this study are to 1) demonstrate the feasibility of the use of standardized patients (SPs) and standardized physicians (SPhs) during a practical examination focused on medical screening, and 2) report outcomes related to the students' abilities to screen for medical issues and make clinical decisions about referral to a physician.

Methods: Students evaluated a standardized patient in an outpatient setting model. After receiving a patient scenario, students chose and performed examination items to identify signs that did not fit with the presenting musculoskeletal complaint. Student performance was scored by the standardized patients based on minimum interview and examination items required. Students discussed the concerns with the standardized patient and stated why the physician needed to be contacted. Students then called the standardized physician to discuss concerns and provide a recommendation.

Results: For the interview portion, $22.8 \pm 18.9 \%$ of students chose all required interview questions and gathered needed information. Most students $(75.5 \pm 14 \%)$ missed 2 or fewer interview items. For the examination portion, $16.7 \pm 16.3 \%$ chose all items and performed them correctly with $59.1 \pm 16.3 \%$ missing 2 or fewer items. Students did well communicating with the standardized patient about calling the physician, with $87.0 \pm 5.3 \%$ scoring $100 \%$. Scores across the affective/communication components were strong $(98.7 \pm 1.7 \%)$. Students were clear when speaking with the physician and made appropriate recommendations based on data collected. Overall feedback from students was positive, but many wanted more time with the standardized patient.

Conclusions: This practical examination allowed students to apply medical screening and differential diagnosis skills in a simulated outpatient encounter. Upon reviewing outcomes for history and examination items, the most challenging part appears to be clinical reasoning. Students had difficulty determining all questions to ask and which items to perform, which reflects that they are novice practitioners. This practical examination was designed to encourage reflection in action, as seen in experienced clinicians, in order to help students progress in their clinical reasoning abilities.
\end{abstract}

\section{Author Bio(s)}

Therese Johnston, PT, PhD, MBA is Associate Professor in the Department of Physical Therapy at the Thomas Jefferson University, Philadelphia, PA. Dr. Johnston is a licensed physical therapist in the state of Pennsylvania.

\section{Acknowledgements}

Dr. Johnston would like to thank E. Adel Herge, OTD, OTL/R, FAOTA for her guidance with the design and implementation of this practical examination. 


\title{
IJAHSP \\ The Internet Joưnal of Allied Health Sciences and Practice
}

Dedicated to allied health professional practice and education

Vol. 16 No. 2 ISSN 1540-580X

\section{Assessment of Medical Screening and Clinical Reasoning Skills by Physical Therapy Students in a Simulated Patient Encounter}

\author{
Therese Johnston, PT, PhD, MBA \\ Thomas Jefferson University \\ United States
}

\begin{abstract}
Purpose: Physical therapists (PTs) screen their patients for medical issues that may present as musculoskeletal conditions. In physical therapy education, learning activities followed by assessment of skills and clinical reasoning is important. The purposes of this study are to 1) demonstrate the feasibility of the use of standardized patients (SPs) and standardized physicians (SPhs) during a practical examination focused on medical screening, and 2) report outcomes related to the students' abilities to screen for medical issues and make clinical decisions about referral to a physician. Methods: Students evaluated a standardized patient in an outpatient setting model. After receiving a patient scenario, students chose and performed examination items to identify signs that did not fit with the presenting musculoskeletal complaint. Student performance was scored by the standardized patients based on minimum interview and examination items required. Students discussed the concerns with the standardized patient and stated why the physician needed to be contacted. Students then called the standardized physician to discuss concerns and provide a recommendation. Results: For the interview portion, $22.8 \pm 18.9 \%$ of students chose all required interview questions and gathered needed information. Most students $(75.5 \pm 14 \%)$ missed 2 or fewer interview items. For the examination portion, $16.7 \pm 16.3 \%$ chose all items and performed them correctly with $59.1 \pm 16.3 \%$ missing 2 or fewer items. Students did well communicating with the standardized patient about calling the physician, with $87.0 \pm 5.3 \%$ scoring $100 \%$. Scores across the affective/communication components were strong $(98.7 \pm 1.7 \%)$. Students were clear when speaking with the physician and made appropriate recommendations based on data collected. Overall feedback from students was positive, but many wanted more time with the standardized patient. Conclusions: This practical examination allowed students to apply medical screening and differential diagnosis skills in a simulated outpatient encounter. Upon reviewing outcomes for history and examination items, the most challenging part appears to be clinical reasoning. Students had difficulty determining all questions to ask and which items to perform, which reflects that they are novice practitioners. This practical examination was designed to encourage reflection in action, as seen in experienced clinicians, in order to help students progress in their clinical reasoning abilities.
\end{abstract}

\section{INTRODUCTION}

Standardized patients (SPs) can be used for summative assessment of students' performance of clinical skills, clinical decision making, and affective components of patient interaction. ${ }^{1}$ Most applications using SPs serve as educational tools for learning rather than as assessments. ${ }^{1,2}$ Panzarella and Manyon described the use of SPs in an integrated physical therapy examination for second year doctor of physical therapy (DPT) students and examined reliability and validity of scoring by SPs. ${ }^{3}$ Panzarella and Manyon found that this model was a unique tool to assess students' abilities to integrate knowledge and skills. ${ }^{3}$ They reported acceptable reliability, however, SPs were more lenient in scoring than were the instructors. ${ }^{3}$

Clinical reasoning skills are important to assess in physical therapy education, as these skills are essential in the current medical environment. Clinical reasoning is a cognitive interactive process in which hypotheses drive decision-making about tests and measures to be perform, which in turn leads to further hypotheses to be tested to identify the physical therapy diagnosis. ${ }^{4,5}$ Clinical reasoning is an essential component of the overall decision making process. ${ }^{5}$

Direct access, in which a patient can see a physical therapist (PT) without a physician's referral, has made it necessary for PTs to have greater medical knowledge and use a differential diagnosis approach that may lead to an appropriate medical referral. ${ }^{6}$

(c) The Internet Journal of Allied Health Sciences and Practice, 2018 
Clinical reasoning in critical in this process. In medical education, objective structured clinical examinations (OSCEs) often attempt to assess clinical reasoning skills along with other important examination skills using SPs. A study by Park et al examined relationships between OSCE performance and clinical reasoning in fourth year medical students. ${ }^{7}$ Items measured on the OSCE included obtaining the history, performing the examination, and affective/communication aspects. Clinical reasoning was measured as the students' abilities to categorize examination findings as being related to specific diagnoses. A diagnostic accuracy score was assigned based on the final diagnosis selected. Park et al did not find that actual scores on the OSCE correlated with scores for clinical reasoning or diagnostic accuracy. Some students were able to provide the correct diagnosis with less information gathered in the OSCE, thus scoring lower on the OSCE itself. ${ }^{7}$ Thus, an OSCE as typically performed in medical schools can assess some skills, but does not provide a strong assessment of clinical reasoning. Alternative or enhanced models of assessment are needed to assess all important skills and more research is needed on techniques to assess these areas.

Clinical reasoning skills are also important to assess in physical therapy education to determine student readiness for clinical practice. The purpose of this report is to demonstrate the feasibility of the use of SPs during a practical examination focused on medical screening and differential diagnosis and to report student outcomes on the examination. The overall goal related to course objectives was to assess students' abilities to apply a clinical reasoning process to screen for medical issues as part of the physical therapy examination. Students were required to make a clinical decision about referring the SP to a physician for items that were not within the physical therapy scope of practice.

\section{METHODS}

To assess examination skills related to differential diagnosis, clinical reasoning, and clinical decision-making, a practical examination was conducted using SPs in a simulated outpatient physical therapy setting. Clinical reasoning and clinical decisionmaking related to signs and symptoms outside of the PT scope of practice were assessed prior to the practical examination with a written exam. Students were in their final didactic semester of the third year of the DPT program and had one fulltime clinical affiliation remaining. Students had three prior full-time clinical affiliations of 8-10 weeks duration with each having at least one in an outpatient setting. Students had completed all clinical courses in neuromuscular, musculoskeletal, cardiopulmonary, and integumentary examination and intervention prior to this practical.

The student sample consisted of 202 third-year DPT students across four consecutive years at a private institution enrolled in a course focused on clinical decision-making and differential diagnosis. In the practical examination, students evaluated a SP in a direct access outpatient model and then called a standardized physician (SPh). Students were instructed prior to the examination that the goal was to perform an interview and examination to screen the SP for medical concerns that would warrant referral to a physician. Students were instructed that they would find one or more reasons that would warrant referral. After receiving a short patient scenario that contained some medical history and a pain diagram, students were required to choose and perform examination items to identify red and yellow flags and any signs that did not fit with a musculoskeletal condition. Following the identification of potential issues, students had to discuss concerns with the SP in layman's terms and state why the physician needed to be called without overly alarming the patient. Students then left the room and prepared to call the SPh (a trained SP acting in a different role) via cell phone. Students had 3 minutes to communicate with the SPh using the Situation, Background, Assessment, Recommendation (SBAR) model of communication. ${ }^{8}$ Students had 3 choices for recommendation: 1) 911 had been called as the issue was an emergency, 2) the physician needs to see the patient right away and that intervention would not be provided, or 3 ) the physician needs to see the patient within the next 2 weeks and that intervention could be safely initiated to alleviate symptoms.

Students received 15 minutes to prepare after receiving the written case, 20-25 minutes with the SP in a private examination room, 7-17 minutes to prepare for the phone call, and three minutes to perform the call. Timing differences were due to the case demands and student feedback across years. The cases differed each year but required similar examination and decision-making skills. Table 1 provides an example of a case similar to the cases used for the practical. In year four, students were given an additional 10 minutes after the phone call to return to the SP to discuss the plan and to receive verbal feedback from the SP. The SPs gave feedback on the overall experience as a patient in the examination scenario, which included items such as communication, affective components, and hands on techniques from the patient's perspective. All students received the graded written feedback.

(c) The Internet Journal of Allied Health Sciences and Practice, 2018 
Table 1: Sample Case and Sample Minimum Required Interview/Examination Items
Information Provided to Students: Renee is a 21-year-old college soccer player who reports "really bad" left shoulder pain upon waking up this morning. She has seen you in the past so begs you to see her that day. She has a big game in two days and wants to be able to play. Her blood pressure is $130 / 85 \mathrm{mmHg}$, heart rate $89 \mathrm{bpm}$, respiratory rate $12 \mathrm{breaths} / \mathrm{min}$, and temperature 98 degrees.
Sample Minimal Required Items (not all inclusive)
1) Past Medical History: significant for a mild concussion 2 years ago and asthma.
2) Family History: Her mother is currently being treated for breast cancer.
3) Interview
a. Pain level: $8 / 10$, constant deep sharp pain in left upper trapezius and left shoulder
b. She treats her asthma with Asmanex twice per day and rescue inhalers as needed. She has been using her inhaler more than usual in the past week (three times/week increased from once/week). She was unable to provide more details on her medications.
c. In practice yesterday, she was hit in the left side of her body and "got the wind knocked out" of her. She cannot identify the exact spot where she was hit. She returned to practice after 20 minutes on the
4) Examination sidelines and completed practice.
a. Shoulder, upper extremity, and cervical active and passive range of motion: all within normal limits.
b. Manual Muscle test in upper extremities: $5 / 5$
c. Lung auscultation: clear to auscultation bilaterally without audible wheezes, rales, or ronchi.
d. Palpation along rib cage: mildly tender which she attributes to increased coughing due to asthma.
e. Palpation of left upper abdominal quadrant (spleen): extreme tenderness along left lower ribs and over spleen with an increase in left shoulder pain. She then tells you that this area has been sore since yesterday.

Assessment: Students should recognize the pain referral patterns in relation to her past medical history and the hard blow in practice yesterday.

Recommendation: Emergency due to possible injured spleen. Send to Emergency Department.

To allow students the opportunity to practice before the practical examination, a group practice session was conducted in class with five practice cases one week prior to the examination. For the first and second year, a student acted as the patient. For the third and fourth, a SP acted as the patient based on student feedback from years one and two related to being able to practice with a SP. The students were provided with cases prior to lab and each student was the primary PT for one case. The other students in each group acted as consultants to the primary PT upon request or as the physician for the practice phone call. Unlike the examination in which students knew they would find a reason to refer, the practice cases varied in severity of medical concerns, requiring no medical referral up to requiring 911 to be called. This approach was used to simulate the range that could be expected in clinical practice. Students in the third and fourth years received feedback from their SP after each practice case. A debriefing session with the primary instructor, lab instructors, and all students was conducted following the students rotating through all cases. Topics of discussion included rationale for history and examination items and factors that led to the clinical decisions. Differing opinions about referral were discussed to clarify why specific recommendations were most appropriate.

One week prior to the practical examination, the course instructor trained the SPs/SPhs in a 2-hour session. The SPs/SPhs received the case and scoring rubric checklists one week prior to the training session to allow them time to read all materials. Regardless of their role, they were instructed on each required item and what constituted correct performance of an item. Demonstrations were provided for all examination items. SPs/SPhs asked questions as needed and were engaged in the process. They routinely act as SPs within the medical school and for other health professions programs within the university in both formative and summative assessments. All SPs are trained by the simulation center to portray affect, simulate physical complaints and examination findings, score students on history taking and physical examination skills, provide a global rating of interpersonal and communication skills, and give feedback to students.

\section{Data Collection}

The governing Institutional Review Board classified the research use of the retrospective data examined as part of this course as exempt. Each year, the instructor identified a list of minimum items that had to be performed related to the case. History and examination items were then scored by the SPs as done (100\%), done but incorrectly (50\% for incomplete or incorrect performance), or not done (0\%). The same scale was used to score communication with the SP as to why the student needed to call the physician. SPs also scored the students on a five point scale from excellent $(100 \%)$ to poor $(0 \%)$ for overall communication/affective skills during the practical exam, including flow of the interview, clarity of questions asked, listening skills,

(c) The Internet Journal of Allied Health Sciences and Practice, 2018 
professional manner, body language, overall affect, delivery of information, and empathy/support. The SPs scored the students' performance electronically on tablet computers containing the scoring rubrics. The SPs wrote comments to clarify items scored as "done but incorrectly" or items they were unsure how to score. All encounters with the SPs were videotaped to allow the instructor to later review performance if grading discrepancies arose after students received their scores. The rooms in which the students made the phone calls were also videotaped. Students and SPs were aware that they were being videotaped. The instructor did not view encounters as they were happening.

The SPhs scored the physician phone call using a rubric based on the SBAR model. They used a checklist created by the course instructor to indicate which required items were reported for situation/background, assessment, and recommendations. The SPhs were instructed to write comments to clarify any items. The checklist allowed the instructor to compare the items reported with the items the student performed when with the SP. Therefore, students were not penalized for making an incorrect decision or recommendation when not all data had been collected during the SP encounter. Their final recommendation was scored based on what was appropriate for the information that they did gather. The course instructor, not the SPhs, determined if the appropriate decision was made by each student.

Immediately following the practical exam, students completed a five-question questionnaire to answer as "strongly agree" to "strongly disagree." These questions asked about examination format and student confidence. Students also completed two open ended sentences: 1) the best part of this experience was _, and 2) if I could change one thing about this experience, I would _. Within a week after the practical examination, students were given the opportunity to view their score sheets and written feedback from the SPs and SPhs and to ask questions of the instructor in a group setting. In year 4, students also received verbal feedback from SPs immediately after the encounter ended due to student feedback from prior years to include this opportunity.

\section{Data Processing and Analysis}

The practical examination counted toward $15 \%$ of the final course grade. Weighting of each section of the examination grading was as follows: interview $30 \%$, physical examination $30 \%$, explanation of the situation to the SP $15 \%$, overall affective/communication with SP 10\%, and physician phone call 15\%. For the interview and examination sections, students received a subscore based on the items completed in relation to items required. For example, if there were five required examination items and the student did three of the five correctly, the score was $60 \%$ for that subsection. That score then accounted for $30 \%$ of the final practical exam grade. For the explanation of the situation to the SP, overall affective/communication with SP, and physician phone call, students received subscores based on the score received for each item rated by the SPs. These scores accounted for the percentages of the final grade as listed above.

To examine the data descriptively, the percentage of students who chose all items and performed them correctly were calculated for the interview and examination sections. Due to the differences in required items across the years, calculating a percent score across all four years would not accurately represent the findings. Descriptive statistics were calculated for top items not performed or performed incorrectly across the four years based on the number of students required to complete each item for the case that year. In addition, descriptive statistics were calculated for student feedback.

\section{RESULTS}

Data were complete for all 202 students across the four years. Students were $28.4 \pm 2.6$ years of age with $73.4 \%$ of students being female. Table 2 shows the results for the interview and examination components of the practical exam in terms of the percentage of items that students chose to perform and performed correctly. For the interview portion, $22.8 \pm 18.9 \%$ of students chose all correct interview questions and were able to gather needed information. Most students $(75.5 \pm 14 \%)$ missed 2 or fewer interview items For the examination portion, $16.7 \pm 16.3 \%$ of students chose all correct items and performed them correctly with $59.1 \pm$ $16.3 \%$ missing 2 or fewer items. There was some variability over the four years, which was anticipated as cases differed each year. Students in year one had the highest scores but the case was less complex compared to subsequent years' cases. Students overall performed better in the interview than the examination across all years. Table 3 shows the items that were most commonly not performed correctly or not performed at all.

(C) The Internet Journal of Allied Health Sciences and Practice, 2018 
Table 2: Percentage of students with the number of exam and interview items not performed or performed incorrectly. The total number of interview items per year was year $1=5$, year $2=10$, year $3=13$, year $4=10$. The total number of examination items per year was year $1=5$, year $2=7$, year $3=8$, year $4=7$.

\begin{tabular}{|c|c|c|c|c|c|}
\hline & $\begin{array}{l}\text { Number of } \\
\text { items not performed or } \\
\text { performed incorrectly }\end{array}$ & $\begin{array}{c}\text { Year } 1 \\
\text { Percent of } \\
\text { Students }\end{array}$ & $\begin{array}{c}\text { Year } 2 \\
\text { Percent of } \\
\text { Students }\end{array}$ & $\begin{array}{l}\text { Year } 3 \\
\text { Percent of } \\
\text { Students }\end{array}$ & $\begin{array}{c}\text { Year } 4 \\
\text { Percent of } \\
\text { Students }\end{array}$ \\
\hline \multirow{6}{*}{ Interview } & 0 & 48.9 & 20.0 & 3.9 & 18.2 \\
\hline & 1 & 37.8 & 44.0 & 30.8 & 16.4 \\
\hline & 2 & 8.9 & 24.0 & 34.6 & 14.6 \\
\hline & 3 & 4.4 & 12.0 & 15.4 & 12.7 \\
\hline & 4 & 0 & 0 & 3.9 & 10.9 \\
\hline & 5 & 0 & 0 & 11.5 & 0 \\
\hline \multirow{7}{*}{ Exam } & 0 & 40.0 & 4.0 & 15.4 & 7.3 \\
\hline & 1 & 31.1 & 12.0 & 21.2 & 9.1 \\
\hline & 2 & 17.8 & 28.0 & 26.9 & 23.6 \\
\hline & 3 & 0 & 38.0 & 15.4 & 40.0 \\
\hline & 4 & 4.4 & 12.0 & 15.4 & 12.7 \\
\hline & 5 & 0 & 6.0 & 3.9 & 7.3 \\
\hline & 6 & 0 & 0 & 1.9 & 0 \\
\hline
\end{tabular}

Table 3: Top items done incorrectly or not done. Not all cases required each of these items so the number of students is reported out of the number that had the case in which the item was required.

\begin{tabular}{|c|c|c|c|c|c|c|}
\hline & $\begin{array}{l}\text { Top } 3 \text { items } \\
\text { done } \\
\text { incorrectly }\end{array}$ & $\begin{array}{l}\text { \# of students } \\
\text { making } \\
\text { error/total \# of } \\
\text { students }\end{array}$ & Comments & $\begin{array}{l}\text { Top } 3 \text { items } \\
\text { not done }\end{array}$ & $\begin{array}{l}\text { \# of students } \\
\text { making } \\
\text { error/total \# of } \\
\text { students }\end{array}$ & Comments \\
\hline \multirow[t]{3}{*}{ Interview } & $\begin{array}{l}\text { Medication } \\
\text { information }\end{array}$ & $15 / 202$ & $\begin{array}{l}\text { Did not ask for } \\
\text { complete } \\
\text { information. }\end{array}$ & $\begin{array}{l}\text { Bowel/bladder } \\
\text { status }\end{array}$ & $25 / 202$ & $\begin{array}{l}\text { Did not ask but } \\
\text { was important } \\
\text { to case. }\end{array}$ \\
\hline & Pain description & $6 / 202$ & $\begin{array}{l}\text { Didn't ask to } \\
\text { describe pain } \\
\text { fully. }\end{array}$ & Pain related & $31 / 202$ & $\begin{array}{l}\text { Missed key } \\
\text { aspects of pain } \\
\text { (i.e. pain scale). }\end{array}$ \\
\hline & $\begin{array}{l}\text { Bowel/bladder } \\
\text { status }\end{array}$ & $2 / 202$ & $\begin{array}{l}\text { Asked about } \\
\text { one but not } \\
\text { other. }\end{array}$ & Night pain & $18 / 157$ & $\begin{array}{l}\text { Did not ask but } \\
\text { warranted by } \\
\text { case. }\end{array}$ \\
\hline \multirow[t]{3}{*}{ Exam } & $\begin{array}{l}\text { Auscultation of } \\
\text { lungs }\end{array}$ & $70 / 157$ & $\begin{array}{l}\text { Did not assess } \\
\text { all needed } \\
\text { areas. }\end{array}$ & $\begin{array}{l}\text { Lymph node } \\
\text { palpation }\end{array}$ & $108 / 157$ & $\begin{array}{l}\text { Did not } \\
\text { examine but } \\
\text { warranted by } \\
\text { case. }\end{array}$ \\
\hline & $\begin{array}{l}\text { Lumbar spine } \\
\text { AROM }\end{array}$ & $63 / 150$ & $\begin{array}{l}\text { Did not perform } \\
\text { repeated } \\
\text { testing or } \\
\text { missed some } \\
\text { directions. }\end{array}$ & $\begin{array}{l}\text { Sensation } \\
\text { related }\end{array}$ & $52 / 202$ & $\begin{array}{l}\text { Did not assess } \\
\text { but warranted } \\
\text { by case. }\end{array}$ \\
\hline & $\begin{array}{l}\text { Lymph node } \\
\text { palpation }\end{array}$ & $36 / 157$ & $\begin{array}{l}\text { Did not assess } \\
\text { in all areas of } \\
\text { concern. }\end{array}$ & $\begin{array}{l}\text { Palpation of } \\
\text { abdomen }\end{array}$ & $38 / 202$ & $\begin{array}{l}\text { Did not perform } \\
\text { but warranted } \\
\text { by case. }\end{array}$ \\
\hline
\end{tabular}






Figure 1: Scores in percentages for students on the phone call with the standardized physician. Students were scored on the clarity of their speaking and on the components of the SBAR model of communication.

Communicating the situation to the SP was scored in the overall communication score in year one as this item was not separated out as in the subsequent years. Across years $2-4,87.0 \pm 5.3 \%$ of the students scored $100 \%, 9.8 \pm 5.3 \%$ scored $50 \%$, and $3.2 \pm$ 2.9 scored $0 \%$ on this component. Students who scored $0 \%$ were those who ran out of time to have a discussion with the SP. In year four, students returned to the SP after the phone call to talk about the plan with $94.4 \%$ of the students scoring $100 \%$ and $5.6 \%$ scoring $50 \%$.

Scores across the affective/communication components were $98.7 \pm 1.7 \%$. Figure 1 shows scores for phone calls with the SPh. Overall students were clear when speaking and made the appropriate recommendation based on data collected. Information that was communicated for situation/background and assessment was inconsistent across the years. While averages were sometimes low, variability was high.

Table 4: Feedback from students immediately after completing the practical. The numbers represent the percentage \pm standard deviation of students across the 4 years who selected each answer. $\mathrm{N}=202$.

\begin{tabular}{|l|c|c|c|c|c|}
\hline & $\begin{array}{c}\text { Strongly } \\
\text { Agree } \\
\text { (percent) }\end{array}$ & $\begin{array}{c}\text { Agree } \\
\text { (percent) }\end{array}$ & $\begin{array}{c}\text { Neutral } \\
\text { (percent) }\end{array}$ & $\begin{array}{c}\text { Disagree } \\
\text { (percent) }\end{array}$ & $\begin{array}{c}\text { Strongly } \\
\text { disagree } \\
\text { (percent) }\end{array}$ \\
\hline $\begin{array}{l}\text { I had enough time to prepare once } \\
\text { given the case. }\end{array}$ & $62.2 \pm 13.4$ & $36.4 \pm 14.1$ & $0.5 \pm 0.9$ & $0.5 \pm 0.9$ & 0 \\
\hline $\begin{array}{l}\text { I had enough time to perform the exam } \\
\text { with the patient. }\end{array}$ & $33.4 \pm 8.7$ & $46.5 \pm 12.8$ & $8.5 \pm 10.2$ & $8.9 \pm 3.5$ & $0.5 \pm 0.9$ \\
\hline $\begin{array}{l}\text { I felt confident in my abilities to perform } \\
\text { the medical screening. }\end{array}$ & $20.4 \pm 7.9$ & $71.8 \pm 4.3$ & $5.7 \pm 4.6$ & $1.0 \pm 1.2$ & 0 \\
\hline $\begin{array}{l}\text { I felt confident in my clinical decision- } \\
\text { making. }\end{array}$ & $24.2 \pm 9.9$ & $65.2 \pm 6.9$ & $8.0 \pm 3.4$ & $1.6 \pm 2.1$ & $0.5 \pm 0.9$ \\
\hline $\begin{array}{l}\text { I felt confident in my abilities to } \\
\text { communicate with the physician. }\end{array}$ & $34.6 \pm 9.9$ & $54.0 \pm 7.5$ & $10.9 \pm 8.0$ & 0 & 0 \\
\hline
\end{tabular}

Overall students felt they had enough time for the practical and felt confident in their abilities to screen, clinical decision make, and communicate with the SPh (Table 4). Table 5 shows sample responses that represent common themes across the open-ended comments. Even though students overall gave feedback scores that indicated they had enough time, many still commented that they wanted more time with the SP. Some students commented on items that they would have liked to do differently, including time manage, organize, and communicate clearer. 
The cost of the practical examination was calculated across the 4 years and averaged $\$ 53.76$ per student. This cost included the SPs and SPhs, simulation lab space and personnel, and phones/minutes. The costs in year four did not increase, as the time allotted for the exam and preparation for the phone call were decreased to allow time for SP verbal feedback.

Table 5: Sample comments upon which changes to the examination were made. Comments only applying to certain years are noted.

\begin{tabular}{|l|l|}
\hline \multicolumn{1}{|c|}{ Positive Comments } & \multicolumn{1}{c|}{ Challenges/Suggestions } \\
\hline $\begin{array}{l}\text { Less intimidating and I was able to fully focus, not as } \\
\text { nervous because it was a SP. }\end{array}$ & $\begin{array}{l}\text { I felt rushed and didn't get a chance to tell the patient I was } \\
\text { leaving to call the physician and why. }\end{array}$ \\
\hline $\begin{array}{l}\text { Realizing we can do a medical screen and make an } \\
\text { impactful decision. }\end{array}$ & More time. \\
\hline $\begin{array}{l}\text { Having to prep and make a physician call because it was } \\
\text { something new. }\end{array}$ & $\begin{array}{l}\text { I would have liked more time to practice exam skills in lab } \\
\text { before this. }\end{array}$ \\
\hline It was very real life and I was able to fully get into character. & Allow for feedback from SP at end (years 1-3). \\
\hline $\begin{array}{l}\text { This helped me to feel comfortable and confident in } \\
\text { performing the tests that were slightly uncomfortable and } \\
\text { necessary to perform. }\end{array}$ & A practice SP session would be helpful (years 1-2). \\
\hline $\begin{array}{l}\text { The SBAR model helped to guide me to effectively } \\
\text { communicate. }\end{array}$ & $\begin{array}{l}\text { More interaction with the physician. I felt like I was talking to } \\
\text { myself and that there was no true dialogue. }\end{array}$ \\
\hline
\end{tabular}

\section{DISCUSSION}

This practical examination was feasible and allowed students to use clinical reasoning to perform a medical screening to make important differential diagnosis and referral decisions in a setting that mimicked an outpatient clinical encounter. The added component of contacting the "physician" allowed students to communicate findings in a succinct manner and better understand the PT's responsibility in a direct access environment. The overall goal was to prepare students for entry-level physical therapy practice. This experience allowed students to practice important examination and decision making skills in a realistic simulated setting. The cost of the examination was feasible within the DPT program budget.

For the required history and examination items, the most challenging part appears to be clinical reasoning as part of clinical decision-making, as students sometimes struggled with choosing the most important items for the patient scenario. Overall students performed selected items correctly indicating skilled performance, but examinations were at times incomplete for lung auscultation and lumbar spine motion. Deciding which questions to ask and which tests to perform was the most challenging, indicating less developed clinical reasoning skills for determining testable hypotheses. Prior to the practical examination, students were instructed that they were required to ask questions and/or perform examination items related to systems in which the SP reported a history or current symptom if it could potentially be related to the musculoskeletal complaint. Table 3 shows the top items not performed. Some are of concern, including asking about bowel and bladder issues and night pain during the interview and performing sensory testing and abdominal palpation that would have reproduced the musculoskeletal complaint during the examination. It is not clear why these items were omitted as students were aware of these important issues when discussing cases during class. Time constraints may have been a factor. Abdominal palpation was a new skill learned in the current course, but repeated motion testing of the lumbar spine and asking about bowel and bladder concerns were not new. In addition, one of the cases involved a woman with a history of breast cancer and gynecological issues but over half of the students (30/55) did not ask about gynecological history in relation to her back pain, despite participating in role playing activities on this topic in class. Health professionals report discomfort with aspects of women's health, thus discomfort discussing breast and gynecological issues may have been a factor. ${ }^{9}$ Comfort has been shown to increase with greater exposure to women and women's health related needs. ${ }^{9}$ Discomfort may also have impacted palpation of important lymph nodes (axillary, femoral, inguinal) due to their location. Future research should examine why some of this important items were missed through a formal debriefing with students.

Missing key examination items is not unique to DPT students. In a study with medical students, Haring et al. used SPs to assess students' abilities to perform a physical examination following an internal medicine clerkship. ${ }^{10}$ Exams were videotaped and scored by physician instructors. The authors found that approximately $40 \%$ of items deemed necessary were not performed. ${ }^{10}$ Park et al. also found that many key items were missed during an OSCE examination for medical students; however many students were able to make the appropriate diagnosis with less information. ${ }^{7}$ This latter finding is difficult to compare to the findings of this practical examination as DPT students' recommendations were scored on the decisions made based on information that they did gather, not on being correct with the recommendation had they performed a complete examination. While the recommendation was not always the most appropriate had all information been gathered, all students recognized at least one potential issue (yellow or red flag) that required communication with the physician.

(C) The Internet Journal of Allied Health Sciences and Practice, 2018 
The errors and omissions made by the students are most likely related to their stage of learning and ability to make clinical decisions. An added challenge to this practical examination was the time allotted, which made students have to process and integrate information quickly to develop new hypotheses and decide how to proceed. Many students wanted more time, with some students spending so much time on the interview that they had little time left for the examination. Students at this point in their education had completed three full-time clinical experiences of eight to ten weeks each, one of which was in an outpatient setting. It was anticipated that they could complete the examination in the allotted time. Despite the desire for more time, many students were very successful in gathering needed information and making the appropriate referral recommendations. Students often report that anxiety associated with a practical examination impacts their abilities, yet a study with chiropractic students found no relationship between anxiety scores and performance on an OSCE. ${ }^{11}$

Wainwright et al compared clinical decision making abilities between novice and experienced PTs, and their findings can provide some insight into clinical decision making for this practical examination. ${ }^{12}$ When making decisions, experts use more directive factors, including movement observation and problem solving as well as their psycho-emotional and cognitive abilities. They use reflection in action, which allows them to use internal and external cues to make decisions and modifications during the patient interaction. ${ }^{12}$ Jensen et al reported that experts use a patient-centered approach that involves more collaboration and problemsolving with the patient (collaborative reasoning). ${ }^{13}$ On the other hand, novices use more informative factors, such as academic knowledge, personal experiences, and anticipated patient performance..$^{12}$ They use reflection on specific action in which decisions are made after the patient interaction or reflection on professional experience in which experiences are used to make decisions beyond a typical one-on-one patient encounter. ${ }^{12}$ As the students taking this practical examination were novices, their decision making abilities would reflect this stage. Gilliland reported that $3^{\text {rd }}$ year DPT students possess clinical reasoning skills more similar to a novice practitioner..$^{14}$ The practical examination was designed to encourage some reflection in action to help students progress in their decision making abilities. Gilliland and Wainwright reported that second year DPT students who were more patient focused in an SP examination and intervention session showed more reflection in action in their clinical reasoning skills. ${ }^{4}$ For this practical examination, perhaps having a follow-up assignment focused on a patient centered approach while reflecting on the encounter would enhance students' abilities to reflect at their current decision making stage, while encouraging further development. In addition, allowing students the opportunity to view and reflect upon their videotaped session would further add to their learning. This opportunity was not provided for logistical reasons as the practical examination occurred at the end of the final didactic semester of the DPT program.

There are limitations of this practical examination approach. Having SPs score the examination may have impacted outcomes. One student reported that she did ask about bowel and bladder issues and upon reviewing the video, the student had done so. As this practical was the last grade entered into their overall course grade, the instructor informed the students that she would review videos for discrepancies if the point difference would impact the final course grade. Three to five students per year requested video review. Other students with concerns about discrepancies may not have requested a video review.

Panzarella and Manyon reported that SPs were more lenient in scoring than instructors. ${ }^{3}$ In this practical examination, leniency in scoring would have only impacted performance scores. As students in this practical struggled more with choosing items, leniency in scoring by SPs would not impact these scores. Another limitation is that students knew that they would find at least one issue that would require referral so they were looking for a non-typical response. Therefore, the outcomes may not fully represent their abilities to integrate these skills into a patient examination. However, the experience may increase their likelihood of doing so.

Future studies to assess the impact of experiences, such as this examination, on future clinical decision-making abilities would be beneficial. Another limitation was the use of SPs as the "physician," as a realistic conversation was not possible. Finally, the use of different cases and some differences in methodology across years is also a limitation in research design, as outcomes are then difficult to compare across years. In conducting examinations that influence student grades, different cases are necessary to ensure that students do not share information across years that could impact scores. Methodological changes were made across the years to incorporate student feedback to improve the learning experience and these changes could have affected the results. Despite these differences, the overall patterns of outcomes were similar.

Students were overall positive about the experience based on their feedback. They enjoyed working with SPs and felt that this approach was more realistic and less intimidating. Many students wanted more time with the SP and others gave suggestions that were incorporated into subsequent years for the course and practical examination. Adding medical personnel to act as the "physician" was considered but not included due to the need to have multiple people available all day and the added cost. While the experience of a conversation would likely be beneficial, it was not the primary focus of this examination.

(C) The Internet Journal of Allied Health Sciences and Practice, 2018 


\section{CONCLUSION}

This practical examination provided insight into areas in which third year DPT students require further development, illustrating that they are at a novice level for clinical reasoning and decision-making. Their clinical decision making abilities were challenged in this setting when they were asked to perform medical screening as part of a 20-25 minute PT evaluation. Students were able to perform key interview and examination items, gather valuable information, and communicate with a "physician." The SPs felt that students communicated well and were strong in the affective components. While students omitted some examination items felt to be important, they were able to identify concerns about the patient that warranted medical referral.

\section{REFERENCES}

1. Pritchard SA, Blackstock FC, Nestel D, Keating JL. Simulated Patients in Physical Therapy Education: Systematic Review and Meta-Analysis. Phys Ther. 2016;96(9):1342-1353.

2. Ryall T, Judd BK, Gordon CJ. Simulation-based assessments in health professional education: a systematic review. $J$ Multidiscip Healthc. 2016;9:69-82.

3. Panzarella KJ, Manyon AT. Using the integrated standardized patient examination to assess clinical competence in physical therapist students. Journal of Physical Therapy Education. 2008;22(3):24-32.

4. Gilliland S, Wainwright SF. Patterns of Clinical Reasoning in Physical Therapist Students. Phys Ther. 2017.

5. Holdar U, Wallin L, Heiwe S. Why do we do as we do? Factors influencing clinical reasoning and decision-making among physiotherapists in an acute setting. Physiother Res Int. 2013;18(4):220-229.

6. Boissonnault WG, Ross MD. Physical therapists referring patients to physicians: a review of case reports and series. $J$ Orthop Sports Phys Ther. 2012;42(5):446-454.

7. Park WB, Kang SH, Lee YS, Myung SJ. Does Objective Structured Clinical Examinations Score Reflect the Clinical Reasoning Ability of Medical Students? Am J Med Sci. 2015;350(1):64-67.

8. Haig KM, Sutton S, Whittington J. SBAR: a shared mental model for improving communication between clinicians. Jt Comm J Qual Patient Saf. 2006;32(3):167-175.

9. Emmons S, Sells CW, Eiff MP. A review of medical and allied health learners' satisfaction with their training in women's health. Am J Obstet Gynecol. 2002;186(6):1259-1265; discussion 1265-1257.

10. Haring CM, Cools BM, van der Meer JW, Postma CT. Student performance of the general physical examination in internal medicine: an observational study. BMC Med Educ. 2014;14:73.

11. Zhang N, Henderson CN. Test anxiety and academic performance in chiropractic students. J Chiropr Educ. 2014;28(1):2-8.

12. Wainwright SF, Shepard KF, Harman LB, Stephens J. Factors that influence the clinical decision making of novice and experienced physical therapists. Phys Ther. 2011;91(1):87-101.

13. Jensen GM, Gwyer J, Shepard KF. Expert practice in physical therapy. Phys Ther. 2000;80(1):28-43; discussion 4452.

14. Gilliland S. Clinical reasoning in first- and third-year physical therapist students. Journal of Physical Therapy Education. $2014 ; 28(3): 64-80$. 